\title{
Functional Characterization of Transporters for L-Aspartate in Bacillus licheniformis
}

\author{
Hanrong Wang 1,2,3, Youran Li 1,2,3,*, Fengxu Xiao ${ }^{1,2,3}$, Yupeng Zhang ${ }^{1,2,3}$, Guiyang Shi ${ }^{1,2,3}$, Liang Zhang ${ }^{1,2,3}$, Sha Xu \\ 1,2,3, Zhongyang Ding 1,2,3 and Zhenghua Gu 1,2,3
}

1 Key Laboratory of Industrial Biotechnology, Ministry of Education, Jiangnan University, Wuxi 214122, China; hanrongw1020@163.com (H.W.); zhangl@jiangnan.edu.cn (L.Z.); xusha1984@jiangnan.edu.cn (S.X.); zyding@jiangnan.edu.cn (Z.D.); guzhenghua2011@163.com (Z.G.)

2 National Engineering Laboratory for Cereal Fermentation Technology, Jiangnan University, 1800 Lihu Avenue, Wuxi 214122, China

3 Jiangsu Provincial Research Center for Bioactive Product Processing Technology, Jiangnan University, 1800 Lihu Avenue, Wuxi 214122, China

* Correspondence: liyouran@jiangnan.edu.cn (Y.L.); Tel.: +86-0510-8591-8235

\begin{abstract}
Amino acid efflux and influx transport systems play vital roles in industrial microorganisms' cell growth and metabolism. However, although biochemically characterized, most amino acid transporters remain unknown at the molecular level in Bacillus licheniformis. This study focuses on the molecular and functional characterizations of three transporters, $\mathrm{YdgF}, \mathrm{YvbW}$, and YveA, mainly when catalyzing the cross-membrane flux of L-Aspartate. When growing in the minimal medium with L-Asp as the only carbon and nitrogen source, the growth of strains lacking proteins $\mathrm{YdgF}, \mathrm{YvbW}$, and YveA was significantly inhibited compared with wild-type strains, while supplementing the expression of the corresponding proteins in the single-gene knockout strains can alleviate the inhibition to some extent. Upon overexpression, the recombinant proteins mediate the accumulation of L-aspartate to varying degrees. Compared with wild-type strains, the single knockout strains of the three protein genes exhibited reduced absorption of L-aspartate. In addition, this paper focuses on the effects of these three proteins on the absorption of $\beta$-alanine, L-glutamate, D-serine, D-alanine, and glycine.
\end{abstract}

Keywords: amino acid permease; L-aspartic acid; Bacillus licheniformis; whole-cell biocatalyst; fermentation engineering

\section{Introduction}

Amino acids are widely used in food, feed, medicine, and cosmetics, and are mainly produced by chemical synthesis, enzyme catalysis, or a combination of the two. Microbial fermentation is often used in the industrial production of amino acids such as glutamic acid, lysine, L-valine, and threonine, given its sound economic and environmental benefits $[1,2]$. However, high concentrations of amino acids inside or outside the cell are often not conducive to fermentation production $[3,4]$. Some amino acid-producing enzymes are inhibited by the substrate; for instance, L-aspartic acid $\alpha$-decarboxylase can be irreversibly inhibited by L-aspartic acid. Excessive intracellular accumulation of certain amino acids will reduce fermentation production and have a toxic effect on cells. For example, a high intracellular concentration of glutamate will produce a negative feedback effect on related synthases, while reducing the intracellular concentration of glutamate weakens the negative feedback effect and improves glutamate production [5]. High intracellular cysteine concentration can lead to DNA damage of the host and have a toxic effect on the producing strain. In the production of alanine fermentation, the high content of intracellular alanine will inhibit cell growth [6]. When amino acids are used as substrates, they cannot be transported into the cell, and thus accumulate in considerable quantities outside the cell, 
leading to reduced fermentation production. Therefore, after the discovery of lysine exporter (LysE), the first amino acid efflux transporter to be discovered, widespread attention was paid to studies that used the transporter to change the concentration of amino acids on both sides of the cell membrane and improved the production of amino acids with recombinant bacteria [7,8]. At present, modifying transporters on the cell membrane to make bacteria more suitable for the biological production of amino acids is an efficient and well-developed bio-engineering method and a research direction with value and prospect [9-18].

Among the existing research on amino acid transporters, there is still insufficient study on L-aspartic acid and its downstream products. Further explorations in this field are significant to the development of the biological production of L-aspartic acid and its downstream products. L-aspartic acid is a common chemical raw material, and it is primarily used to produce food additives, synthetic sweeteners, synthetic biopolymer PASP, synthetic new drugs, clinical medicine, and intermediates in the synthesis of other products. In the early stages of industrial production, the traditional microbial fermentation method based on saccharide was adopted, but there was a long production cycle, with many by-products and high technical risks [19-21]. $\beta$-alanine is a naturally occurring $\beta$ type amino acid. It is not directly involved in protein synthesis in organisms, yet it is a potential functional amino acid. The reported biosynthesis method is to decarboxylate LAsp with PanD enzyme (L-aspartic acid $\alpha$-decarboxylase) in organisms. $\beta$-alanine is a crucial substance widely used in the production of medicine, healthcare products, chemical products, fodder, etc. At present, the production of $\beta$-alanine in China is mainly based on the chemical synthesis of strong acid and alkali hydrolysis under high temperatures and pressures [22, 23]. However, in view of the development needs of a green and environmentally friendly economy, the biosynthesis method with mild reaction conditions and environmental friendliness is a more favorable option. Therefore, it is of great practical value to improve the strain's production efficiency by modifying the membrane's ability to transport amino acids and construct engineering bacteria suitable for producing L-Asp, $\beta$-Ala, and most other amino acids.

Bacillus licheniformis is rich in enzymes, with a moderate growth rate, full protein folding, and many advantages that other industrial strains do not have. It was recognized as a food-safe strain (GRAS) over 40 years ago [24, 25]. As a platform for homologous or heterogeneous expression, it is a good industrial microbial strain widely used in the production of food enzymes and antibiotics. B. licheniformis is a thermophile, which can grow well at $40-50{ }^{\circ} \mathrm{C}$. It can secrete peptides to inhibit the growth of other bacteria and fungi during the fermentation process, and thus is not easy to be infected by bacteria. B. licheniformis is rich in enzymes, can produce large quantities of enzymes, and has an extracellular protein secretion that can reach twice that of Bacillus subtilis. Meanwhile, it has strong stress resistance, is hardly soluble, and can be reused [26]. Nevertheless, there are many characteristics of $B$. licheniformis that need to be further investigated. As a food-safe strain for industrial production, $B$. licheniformis has a great potential in amino acid production, although the research on amino acid transporters of B. licheniformis is still scarce. It has been studied that Cody, a transcription factor that can regulate the amino acid permease, can prevent lichenysin biosynthesis under the amino acid-rich condition in B. licheniformis, and BCAAs can relieve this inhibition. In addition, knocking out the amino acid transporter gene $y h d G$ can improve the yield of bacitracin [10, 27, 28]. At present, there is still not enough research in this field. An in-depth study on the function or transport mechanism of the transporter on the cell membrane of B. licheniformis can facilitate the exploration of its future applications, so that this strain can be applied to the production of foodsafe amino acid products with higher efficiency and more environmental friendliness.

Some proteins are predicted to be related to amino acid permeases. The genes of these proteins are in the genome of Bacillus licheniformis CICIM B1391, which can be found on NCBI. The function of certain enzymes with amino acid permeability has been determined. At the same time, there are still quite a few proteins that are merely predicted to function as amino acid transporters in certain ways, indicating that they belong to amino 
acid permeases, but their specific functions remain unclear. The sequences of amino acid transporters found on NCBI were made into an evolutionary tree (shown in supplementary materials). The YveA protein has been identified to be the L-Asp transporter in $B$. subtilis; in this study, apart from gene $y v e A$, we also selected genes $y d g F$ and $y v b W$ from the evolutionary tree, whose fragments are similar to yveA. Little research has been conducted on the specific functions of amino acid transporters YdgF, YvbW and YveA expressed by these three genes in B. licheniformis. Therefore, these three proteins are the main research objects in this study [30]. The YdgF protein, a member of the small multidrug resistance (SMR) family of transporters in the inner membrane, is predicted to have the function of transporting D-serine, D-alanine, and glycine [29-33]. The function of YvbW protein in B. subtilis is to transport leucine and participate in leucine metabolism, and its expression is regulated by leucine concentration. YvbW is also a BCAA permease identified as BCAA importers, whose overexpression improves intracellular BCAA accumulations and bacitracin yields. Demonstrated to be transcribed as a monocistronic mRNA containing a prototypical $\mathrm{T}$ box antitermination leader, YvbW can transport a precursor for leucine, isoleucine, valine, or glutamate biosynthesis [34, 35]. YveA is a putative transporter of the amino acid / polyamine / organocation (APC) superfamily and the first member of a new family within the APC superfamily. YveA of B. subtilis is the only characterized member of the AGT family. As reported, YveA is shown to be able to mediate the uptake of both L-aspartate and L-glutamate in B. subtilis [36, 37].

This paper focuses on the transport of L-Asp and other related amino acids by three types of amino acid permeases on the cell membrane of B. licheniformis. Using food-safe strains like $B$. licheniformis to produce amino acids through whole-cell catalysis is an environmentally friendly and safe method with broad application prospects. To make cells adapt to amino acid production through genetic engineering, we must first comprehend the function of amino acid transporters on cell membranes. Whole-cell catalysis adopts the complete biological organism as a catalyst for chemical transformation. The reaction solution has a simple composition and is easy to purify and examine. In addition, the cell contains a complete enzyme reaction system and necessary cofactors, which makes this approach more suitable for the experiment compared to the traditional fermentation method. In this study, the whole-cell catalysis method was used to analyze the function of the protein.

\section{Results}

\subsection{Construction of Plasmids and Strains}

Since the functions of amino acid permeases $\mathrm{YdgF}, \mathrm{YvbW}$, and YveA are still not clear, these three proteins were selected as the research objects, and their genes are $y d g F$, $y v b W$, and $y v e A$, respectively. The DNA sequences of genes $y d g F, y v b W, y v e A$ were researched by NCBI. Using the genome of B. licheniformis CICIM B1391 as a template, genes $y d g F, y v b W$, and yveA were amplified with PCR. In order to overexpress proteins YdgF, YvbW, and YveA in strains, the amplified fragments were connected to the shuttle plasmid pHY300-PLK, which can be expressed in both E. coli and B. licheniformis. It is not clear which promoter can mediate the overexpression of the protein; hence mannitol inducible promoters PmtlA [38], Pshuttle09 [39], shuttle09 with xylose inducible site Pshuttle09-XBS were selected to mediate the expression of the transporter. With this method, the constructed plasmid was transformed into B. licheniformis. Nine strains with permease genes overexpression were constructed, namely BlpMF, BlpS09F, BlpS09XF, BlpMW, BlpS09W, BlpS09XW, BlpMA, BlpS09A, and BlpS09XA, as shown in Table 1. In order to verify whether the plasmid is correctly constructed, the promoter fragments and the expressed protein gene fragments were cut from the plasmid with double-enzyme digestion. The verification was conducted with nucleic acid electrophoresis. The results are shown in Figures $1 \mathrm{~A}, \mathrm{~B}$, and C. 
A.

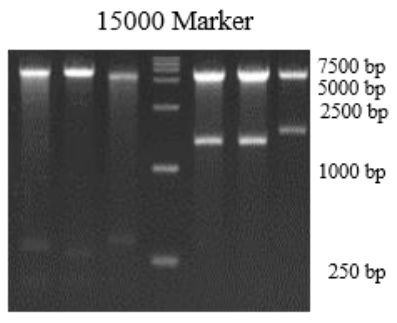

C.

2000 Marker 10000 Marker

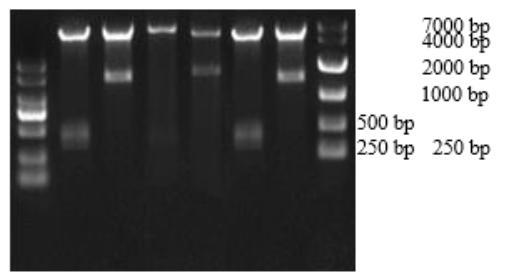

E.

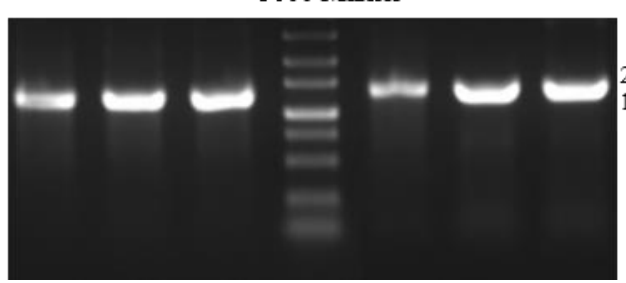

B.

D.

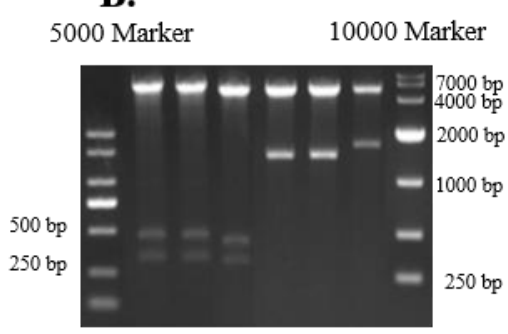

15000 Marker 10000 Marker

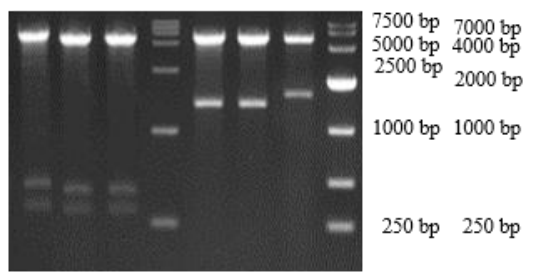

F.

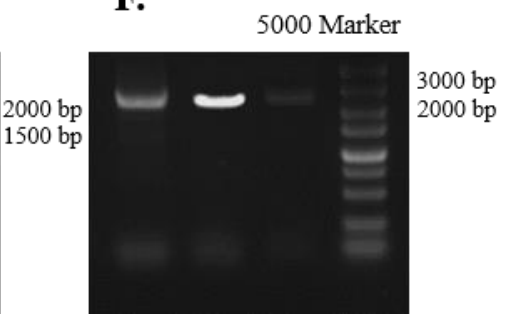

Figure 1. DNA fragments and nucleic acid electrophoresis in the construction of the strain. (A) (B) (C) The nucleic acid electrophoretogram of the fragments obtained after double-enzyme digestion of the overexpressed protein particles. The overexpression of genes $y d g F, y v b W$, and yveA was mediated by different promoters in B. licheniformis. (A) The overexpression of the three genes mediated by promoter PmtlA; (B) The overexpression of the three genes mediated by promoter Pshuttle09; (C) The overexpression of gene $y d g F$ mediated by promoter Pshuttle09-XBS; (D) Nucleic acid electrophoresis of gene fragments of the expressed protein on the plasmid and PCR amplified promoter fragments; (E) (F) The nucleic acid electrophoretogram when verifying whether three genes are knocked out separately in B. licheniformis CICIM B1391; (E) The left exchange and right exchange of the three single knockout strains; (F) The double exchange of the three single knockout strains.

Table 1. Bacterial strains and plasmids used in this study

\begin{tabular}{|c|c|c|}
\hline Strain and plasmid & Genotype or phenotype & Reference \\
\hline \multicolumn{3}{|l|}{ Plasmid } \\
\hline pHY300-PLK & E. coli/Bacillus shuttle vector, $\mathrm{Ap}^{\mathrm{R}} / \mathrm{Tet}^{\mathrm{R}}$ & TaKaRa \\
\hline pMD19T-simple & E. coli cloning vector, $\mathrm{Ap}^{\mathrm{R}}$ & TaKaRa \\
\hline pNZT1 & $\begin{array}{l}\text { The delivery vector of replication } \\
\text { thermosensitive and rolling circle amplification, } \\
\mathrm{Em}^{\mathrm{R}}\end{array}$ & Laboratory construct \\
\hline pNZTT & pNZT1 inset a tetracycline gene for Tet ${ }^{\mathrm{r}}$ at Not & Laboratory construct \\
\hline $\mathrm{pMF}$ & $\begin{array}{l}\text { Promoter PmtlA mediated protein YdgF } \\
\text { overexpression }\end{array}$ & This work \\
\hline
\end{tabular}




\begin{tabular}{|c|c|c|}
\hline pS09F & $\begin{array}{l}\text { Promoter Pshuttle09 mediated protein YdgF } \\
\text { overexpression }\end{array}$ & This work \\
\hline pS09XF & $\begin{array}{l}\text { Promoter Pshuttle09-XBS mediated protein YdgF } \\
\text { overexpression }\end{array}$ & This work \\
\hline pMW & $\begin{array}{l}\text { Promoter PmtlA mediated protein YvbW } \\
\text { overexpression }\end{array}$ & This work \\
\hline pS09W & $\begin{array}{l}\text { Promoter Pshuttle09 mediated protein YvbW } \\
\text { overexpression }\end{array}$ & This work \\
\hline pS09XW & $\begin{array}{l}\text { Promoter Pshuttle09-XBS mediated protein } \\
\text { YvbW overexpression }\end{array}$ & This work \\
\hline pMA & $\begin{array}{l}\text { Promoter PmtlA mediated protein YvbA } \\
\text { overexpression }\end{array}$ & This work \\
\hline pS09A & $\begin{array}{l}\text { Promoter Pshuttle09 mediated protein YvbA } \\
\text { overexpression }\end{array}$ & This work \\
\hline pS09XA & $\begin{array}{l}\text { Promoter Pshuttle09-XBS mediated protein YvbA } \\
\text { overexpression }\end{array}$ & This work \\
\hline $19 \mathrm{~T}-y d g f$ & $\begin{array}{l}\text { pMD19T-simple with the } y d g F \text { fragment and its } \\
\text { homology arm }\end{array}$ & This work \\
\hline 19T-yvbw & $\begin{array}{l}\text { pMD19T-simple with the } y v b W \text { fragment and its } \\
\text { homology arm }\end{array}$ & This work \\
\hline 19T-yvea & $\begin{array}{l}\text { pMD19T-simple with the yveA fragment and its } \\
\text { homology arm }\end{array}$ & This work \\
\hline 19T-FFKF & pMD19T-simple with the deletion cassette of $y d g f$ & This work \\
\hline $19 \mathrm{~T}-\mathrm{WFKF}$ & $\begin{array}{l}\text { pMD19T-simple with the deletion cassette of } \\
\text { yobw }\end{array}$ & This work \\
\hline 19T-AFKF & pMD19T-simple with the deletion cassette of yvea & This work \\
\hline pNZTT-FFKF & $\begin{array}{l}\text { Knock-out vector pNZTT with the deletion } \\
\text { cassette of } y d g F\end{array}$ & This work \\
\hline pNZTT-WFKF & $\begin{array}{l}\text { Knock-out vector pNZTT with the deletion } \\
\text { cassette of yvbw }\end{array}$ & This work \\
\hline pNZTT-AFKF & $\begin{array}{l}\text { Knock-out vector pNZTT with the deletion } \\
\text { cassette of yvea }\end{array}$ & This work \\
\hline air & & \\
\hline
\end{tabular}


$\mathrm{F}^{\prime}$, traD36, proAB + lacIq, $\Delta($ lacZ), M15/ $\Delta$ (lac-

E. coli JM109

Bacillus licheniformis CICIM B1391

BldF

BldW

BldA

BlpMF

BlpS09F

BlpS09XF

BlpMW

BlpS09W

BlpS09XW

BlpMA

BlpS09A

BlpS09XA

BlpHY

BldFpHY

BldWpHY
proAB), gln V44, e14-, gyrA96, recA1, relA1,

endA1, thi, hsdR17 (CICIM B0012)

Wild type (CICIM B1391)

CICIM-CU

Bacillus licheniformis CICIM B1391, knockout of ydgF gene, Kan ${ }^{\mathrm{r}}$

Bacillus licheniformis CICIM B1391, knockout of yobW gene, Kan ${ }^{\mathrm{r}}$

Bacillus licheniformis CICIM B1391, knockout of yveA gene, Kan ${ }^{\mathrm{r}}$

Bacillus licheniformis CICIM B1391, harboring pMF

Bacillus licheniformis CICIM B1391, harboring pS09F

Bacillus licheniformis CICIM B1391, harboring pS09XF

Bacillus licheniformis CICIM B1391, harboring pMW

Bacillus licheniformis CICIM B1391, harboring pS09W

Bacillus licheniformis CICIM B1391, harboring pS09XW

This work

This work

This work

This work

This work

This work

This work

This work

This work

Bacillus licheniformis CICIM B1391, harboring pMA

This work

Bacillus licheniformis CICIM B1391, harboring pS09A

Bacillus licheniformis CICIM B1391, harboring pS09XA

Bacillus licheniformis CICIM B1391, harboring pHY300-PLK

This work

Bacillus licheniformis CICIM B1391, dydgF,

harboring pHY300-PLK

This work

Bacillus licheniformis CICIM B1391, dyobW,

harboring pHY300-PLK

This work 


\begin{tabular}{|c|c|c|c|c|c|}
\hline BldApHY & $\begin{array}{l}\text { Bacillus licheniformis } \\
\text { harboring pHY300-PLK }\end{array}$ & CICIM & B1391, & $\mathrm{d} y v e A$ & This work \\
\hline BldFpS09F & $\begin{array}{l}\text { Bacillus licheniformis } \\
\text { harboring pS09F }\end{array}$ & CICIM & B1391, & $\mathrm{d} y d g F$ & This work \\
\hline BldWpS09W & $\begin{array}{l}\text { Bacillus licheniformis } \\
\text { harboring pS09W }\end{array}$ & CICIM & B1391, & $\mathrm{d} y v b w$ & This work \\
\hline BldApS09A & $\begin{array}{l}\text { Bacillus licheniformis } \\
\text { harboring pS09A }\end{array}$ & CICIM & B1391, & $\mathrm{d} y v e A$ & This work \\
\hline
\end{tabular}

${ }^{1} \mathrm{~A} \mathrm{p}^{\mathrm{R}}$, ampicillin resistance; $\mathrm{Tet}^{\mathrm{R}}$, tetracycline resistance; $\mathrm{Kan}^{\mathrm{R}}$, kanamycin resistance; $\mathrm{Em}^{\mathrm{R}}$, erythromycin resistance ${ }^{2}$ CICIM-CU: Culture and Information Center of Industrial Microorganisms of China Universities

Taking B. licheniformis CICIM B1391 as the starting strain, the $y d g F, y v b W$, and $y v e A$ genes were removed from the chromosome according to method 4.2. To acquire single knockout strains BldF, BldW, and BldA, respectively. The nucleic acid electrophoresis results of PCR fragments of left exchange, right exchange, and double exchange used for verification when knocking out genes from the strain genome are shown in Figures 1E and F.

The corresponding transporter genes were supplemented and expressed in the single-gene knockout strains. The plasmid overexpressing the transporter genes mediated by the shuttle09 promoter was transformed into the strain where the transporter genes have been knocked out, and strains BldFpS09F, BldWpS09W, and BldApS09A were constructed. For comparison, the empty plasmid was also transformed into three single-gene knockout strains, and strains BldFpHY, BldWpHY, BldWpHY were constructed. The transporter gene and promoter gene on the plasmid in the strain were amplified to ensure the transformation of the plasmid into the strain, which was verified by nucleic acid electrophoresis. The results are shown in Figure 1D.

2.2. Effects of Transport protein Expression Changes on Strain Growth in a Minimal Medium with Free L-Asp as the Sole Carbon and Nitrogen Source

2.2.1. Growth Curves of Single-Gene Knockout Strains in a Minimal Medium with Free L-Asp as the Only Carbon and Nitrogen Source

Strains BldF, BldW, and BldA were activated and inoculated into $30 \mathrm{~mL}$ of minimal medium with L-Asp at a concentration of $2 \mathrm{~g} / \mathrm{L}$ as the only carbon and nitrogen source. The strains were grown at $37{ }^{\circ} \mathrm{C}$ at a centrifugation speed of $250 \mathrm{rpm}$, and the wild-type strain was used as a control. The absorbance at $600 \mathrm{~nm}$ of the fermentation broth was measured every 3 hours. With the obtained data, origin 9 was used to make a line graph of OD600 over time, and then nonlinear fitting was performed on the line graph. The curve (growth curve) of OD600 over time is shown in Supplementary Material. The derivative of the fitted curve is obtained and divided by OD600 to obtain the specific growth rate curve of strains. The results are shown in Figure 2A. 
A.

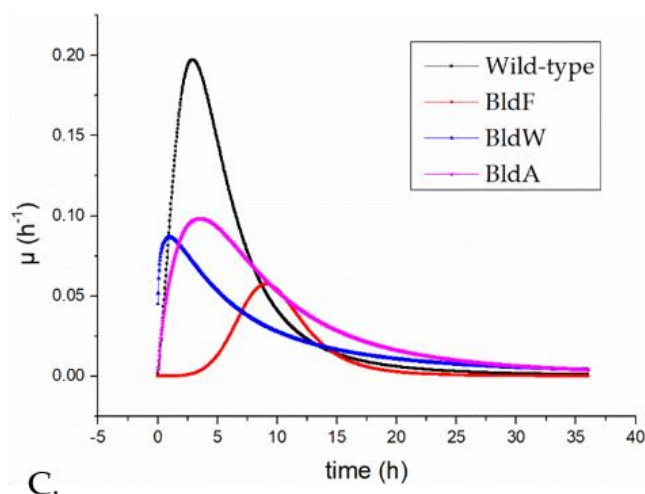

C.

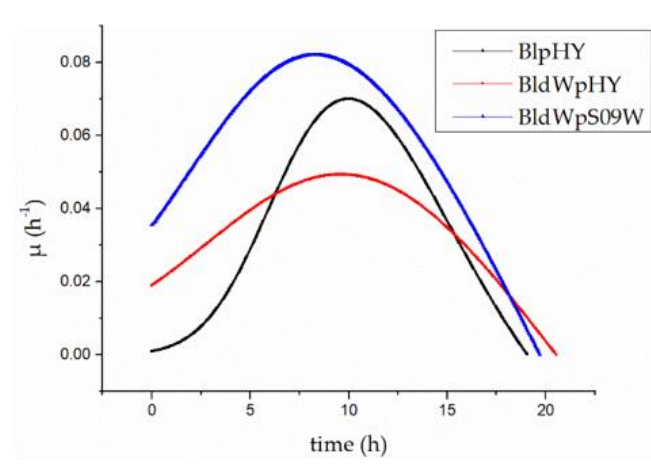

B.

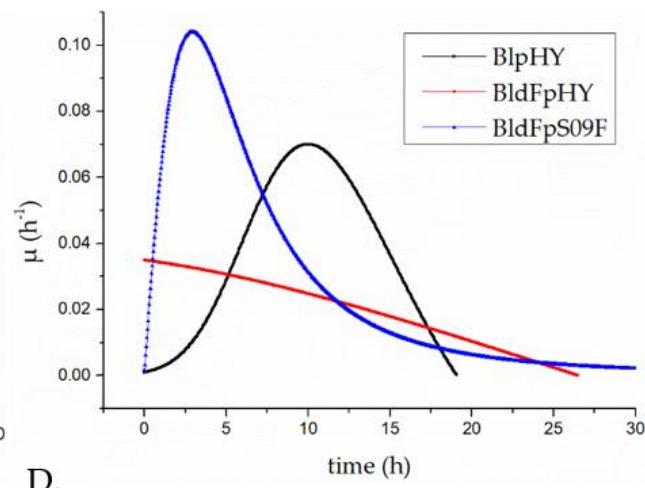

D.

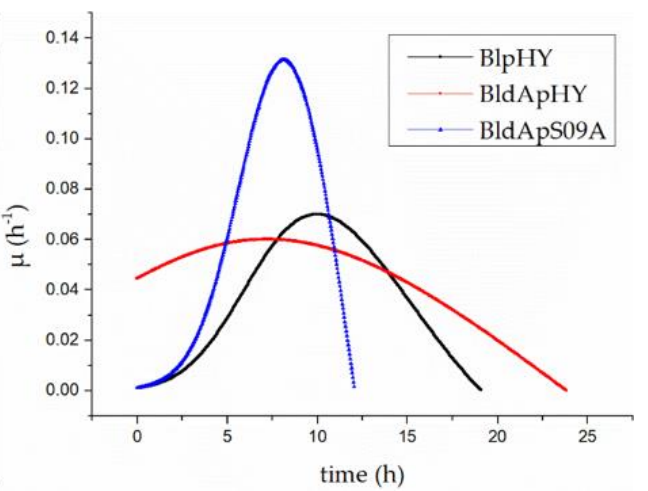

Figure 2. Specific growth rate curve of strains when using a minimal medium with free L-Asp as the only carbon and nitrogen source. (A) The specific growth rate curves of the wild-type strain (black), strain BldF (red), strain BldW (blue), and strain BldA (pink); (B) (C) (D) Strains BlpHY (black), BldFpHY (red) and transporter gene single knockout strains with plasmids with overexpressed transporter mediated by promoter Pshuttle09, which means the transport protein gene is supplemented and expressed in the strains with single knockout transporter gene (blue); (B) Specific growth rate curve of strain BldFpS09F; (C) Specific growth rate curve of strain BldWpS09W; (D) Specific growth rate curve of strain BldApS09A.

It is clear from Figure 2A that the specific growth rate of the strains without a transport protein is significantly lower than that of the wild-type strain when the concentration of L-Asp is $2 \mathrm{~g} / \mathrm{L}$. The highest specific growth rate of the wild-type strain can reach $0.197 \mathrm{~h}^{-1}$. The highest specific growth rates of the three strains lacking transport proteins are all lower than $0.1 \mathrm{~h}^{-1}$. The highest specific growth rate of BldF is $0.057 \mathrm{~h}^{-1}$, $0.086 \mathrm{~h}^{-1}$ for BldW, and $0.098 \mathrm{~h}^{-1}$ for BldA, which are much lower than that of the wildtype strain, indicating that the growth rate of the wild-type strain is higher than strains BldF, BldW, and BldA, and the growth of the strains was inhibited to varying degrees after the transporter gene was knocked out, which means the optimum growth of strains requires the existence of these three transport proteins. It also shows that proteins $\mathrm{YdgF}$, YvbW, and YveA have different effects on L-Asp absorption.

2.2.2. Growth Curves of Single Knockout Strains Supplemented with Genes Expressing Corresponding Transporters in a Minimal Medium with Free L-Asp as the Only Carbon and Nitrogen Source

Strains BldFpS09F, BldWpS09W, and BldApS09A were activated and inoculated into $30 \mathrm{~mL}$ of minimal medium with L-Asp at a concentration of $2 \mathrm{~g} / \mathrm{L}$ as the only carbon and nitrogen source. The strains were grown at $37{ }^{\circ} \mathrm{C}$ at a centrifugation speed of $250 \mathrm{rpm}$, and strains BldFpHY, BldWpHY, BldApHY, and BlpHY were used as controls. The absorbance of the fermentation broth at $600 \mathrm{~nm}$ was measured every 3 hours. The obtained data was processed in the same way as described in 2.4.1. The results are shown in Figures 2B, C, D, and the growth curves are shown in Supplementary Materials.

It can be found from Figure 2 that supplementing the corresponding protein in a strain lacking transport proteins can significantly alleviate the inhibition and return the cell proliferation to normal to some extent. The three proteins' abilities in alleviating the 
inhibition are different. The highest specific growth rate of the wild-type strain with empty plasmid was $0.07 \mathrm{~h}^{-1}$. The maximum specific growth rate of strain BldFpS09F was $0.104 \mathrm{~h}^{-1}, 0.082 \mathrm{~h}^{-1}$ for strain BldWpS09W, and $0.131 \mathrm{~h}^{-1}$ for strain BldApS09A, which are significantly higher than that of BlpHY, indicating that the biomass concentrations of strains with retro-complementation of the corresponding transport proteins increase more rapidly than the wild-type strain with an empty plasmid. Strain BldFpS09F proliferated rapidly in the early stages, partly making the growth of the strain return to normal (Figure 2B). Although it is not significantly higher than the complementary expression of YdgF and YveA, the specific growth rate of strain BldWpS09W is higher than that of the control group, and the growth of the strain has returned to normal (Figure 2C). The maximum specific growth rate of strain BldApS09A was significantly higher than strain BlpHY, and the peak appeared earlier, indicating that the cell count of strain BldApS09A increased rapidly in the early stages, which alleviated the inhibitory effect caused by the absence of the transport protein (Figure 2D).

\subsection{Effect of Strains Overexpressing Amino Acid Permease Gene on L-Asp Absorption}

In order to study how changes in the expression of $y d g F, y v b W$, and yveA affect the absorption of L-aspartate, nine strains overexpressing the three proteins were activated and inoculated into the fermentation medium. The sample was centrifugated for $15 \mathrm{~min}$ at $9000 \mathrm{rpm}$. The cells were collected when OD600 was about 10. The effects of the overexpression of YdgF, YvbW, and YveA on the absorption of L-Asp in wild-type strains were used as a comparison according to method 4.4. The OD600 of cell suspension was about 150. The results are shown in Figure 3.

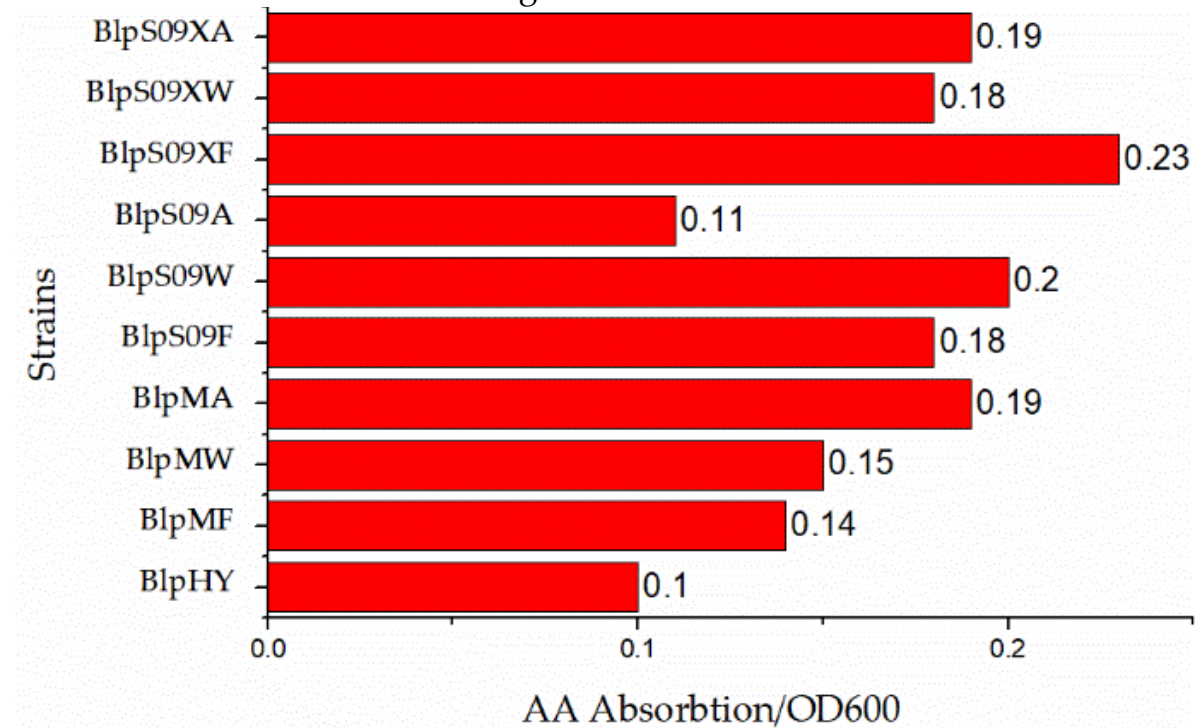

Figure 3. The ratio of extracellular L-aspartic acid concentration to the cell concentration of the strains overexpressing amino acid permease=

This figure shows how the L-Asp absorption was affected by the overexpression of the three transporters mediated by different promoters when the L-Asp concentration was $20 \mathrm{~g} / \mathrm{L}$ and reaction time was $16 \mathrm{~h}$. The strain BlpHY was used as a comparison.

It can be known that the ratio of extracellular L-Asp concentration to cell concentration of the strain overexpressing protein $y d g F$ is significantly lower than that of a wildtype strain with an empty plasmid, indicating that the overexpression of protein $\mathrm{YdgF}$ can improve the absorption of L-Asp by the cells (the ratio of extracellular L-Asp concentration to cell concentration was $62.5 \%$ higher than that of the wild-type strain with an empty plasmid when Pshuttle09-XBS promoter was used to mediate protein overexpression). The overexpression of both YvbW and YveA proteins can improve the absorption of L-Asp to 
a certain extent. It can also be seen from the figure that when the Pshuttle09-XBS promoter functioned as the mediator, the expression of the protein was the highest.

\subsection{Effects of the Absence of Amino Acid Permease Genes on L-Asp Absorption}

The three strains overexpressing the three proteins activated and collected cells in the same way, as shown in 2.3. According to method 4.4, the strain BlpHY was used as a control to study the effect of the absence of amino acid permease genes $y d g F, y v b W$, and $y v e A$ on L-Asp absorption. The OD600 of cell suspension was about 150.

This figure shows how knocking out three amino acid permease genes from the strain affected L-Asp absorption when the L-Asp concentration was $20 \mathrm{~g} / \mathrm{L}$ and reaction time was $16 \mathrm{~h}$. The wild-type strain was used as a comparison. The results are shown in Figure 4.

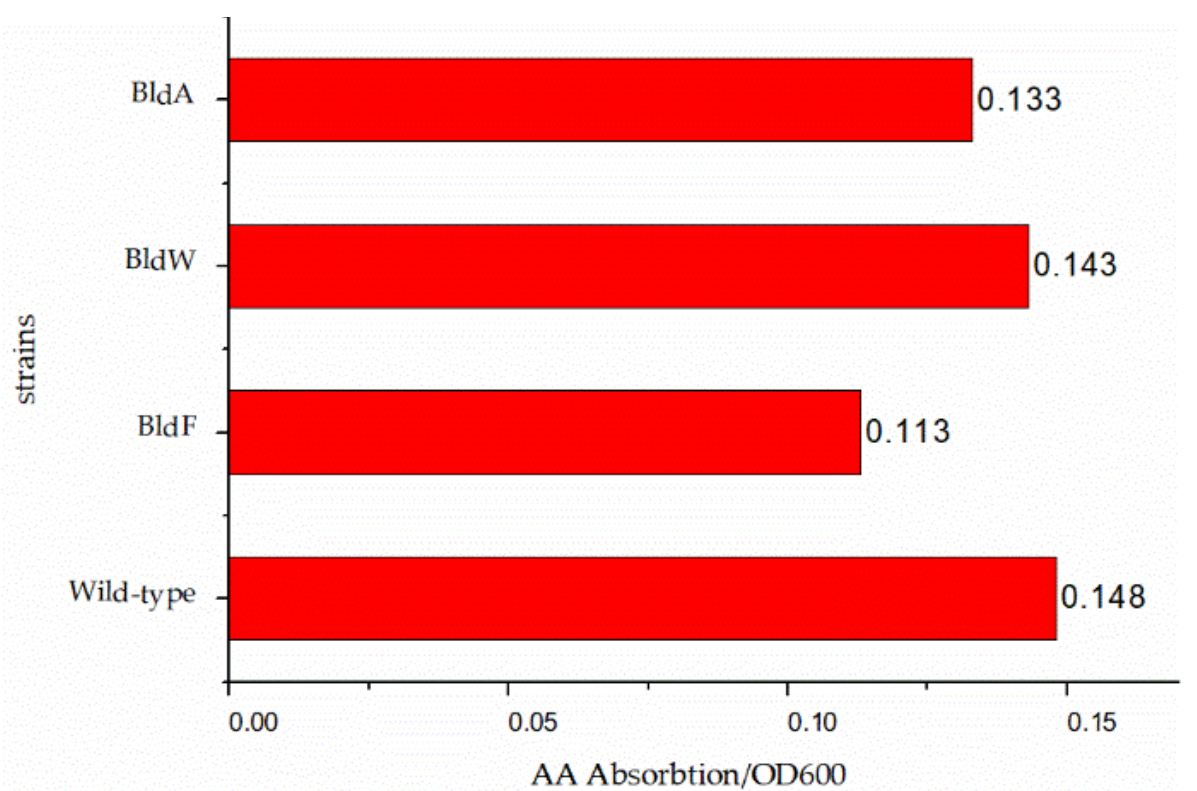

Figure 4. The ratio of the concentration of extracellular L-aspartic acid to the cell concentration of the strain lacking amino acid permease

It can be seen that in the strain lacking the expression of the three proteins, the ratio of extracellular L-Asp concentration to cell concentration is significantly higher than that of the wild-type strain, indicating that the absence of the expression of the three proteins weakens the absorption of L-Asp, which is generally consistent with the effect of the overexpression of permease proteins on L-Asp absorption.

2.5. Effects of the Three Transport proteins on the Transportation of Other Amino Acids by Bacillus licheniformis

In order to test whether these three proteins can transport other amino acids, the amino acids predicted to be transported by the three transporters were selected as the research objects. Strains BlpHY, BlpS09XF, BlpS09XW, and BlpS09XA were activated and collected according to method 4.4. $\beta$-alanine, D-serine, D-alanine, glycine, and L-glutamic acid solutions were respectively added to make the final concentration of amino acid 20 $\mathrm{g} / \mathrm{L}$. The effects of the overexpression of three proteins on the absorption of these four amino acids in wild-type strains were used as a comparison. The results are shown in Figure 5. 


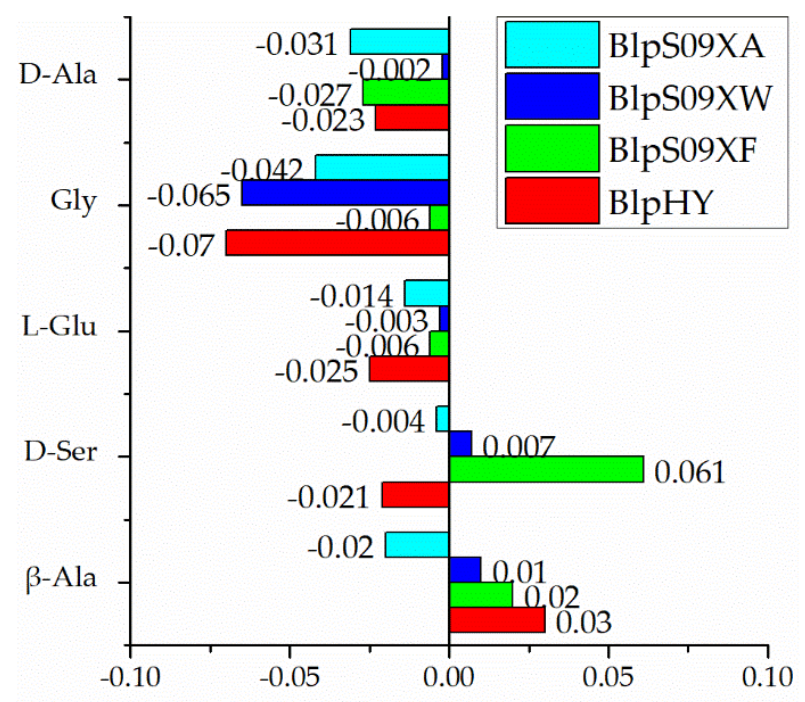

AA Absorbtion/OD600

Figure 5. The ratio of the extracellular $\beta$-Ala, D-Ser, Gly, L-Glu, and D-Ala concentrations of strains overexpressing amino acid permease mediated by promoter Pshuttle09-XBS to the cell concentration

It can be seen from the figure that the ratio of the extracellular $\beta$-Ala concentration of strain BlpS09XA to the cell concentration is higher than that of strain BlpHY, indicating that the strain overexpressing YveA has a lower $\beta$-Ala absorption than the wild-type strain, i.e., the overexpression of $y v e A$ hinders the absorption of $\beta$-Ala. The overexpression of $\mathrm{YdgF}$ and $\mathrm{YvbW}$ proteins hardly affected $\beta$-Ala absorption of the B. licheniformis cells. As for the other amino acids, it can be seen from the figure that the ratio of the concentration of D-Ser, L-Glu, and Gly absorbed by cells to the cell concentration is significantly higher than that of wild-type strains with empty plasmids, indicating that the overexpression of protein YdgF can improve the absorption of D-Ser, L-Glu, and Gly. However, the ratio of D-Ala absorbed by cells to cell concentration is lower than that of strain BlpHY, indicating that the absorption of D-Ala is weakened. The overexpression of YvbW protein can enhance the absorption of D-Ser and D-Ala, but changes in the transport of L-Glu and Gly are not obvious. The overexpression of the YveA protein can improve the absorption of D-Ser and L-Glu, and weaken the absorption of Gly and D-Ala.

\section{Discussion}

At present, there is still not enough research on the amino acid transporters on the cell membrane of $B$. licheniformis and on using $B$. licheniformis as a whole-cell catalyst. $B$. licheniformis is an excellent production strain with significant research value and huge potential for further explorations. From current research and prediction, it can be known that protein $\mathrm{YdgF}$ can transport D-serine, D-alanine, and glycine. The function of protein YvbW in B. subtilis is leucine transport; it participates in leucine metabolism while its expression is regulated by leucine concentration. Protein YveA is known to be related to the transport of L-aspartate and L-glutamate in other Bacilli. In this study, the three transporter genes $y d g F, y v b W$, and $y v e A$ in the genome of B. licheniformis CICIM B1391 were cloned, and their expression changed in B. licheniformis. The changes in amino acid transport capacity were studied through whole-cell catalysis. We also knocked out these three genes from the genome of B. licheniformis CICIM B1391, constructed three single knockout strains, and observed their growth with the designated amino acid as the only carbon and nitrogen source. Finally, the transport effects of the three proteins on some other amino acids were also studied. 


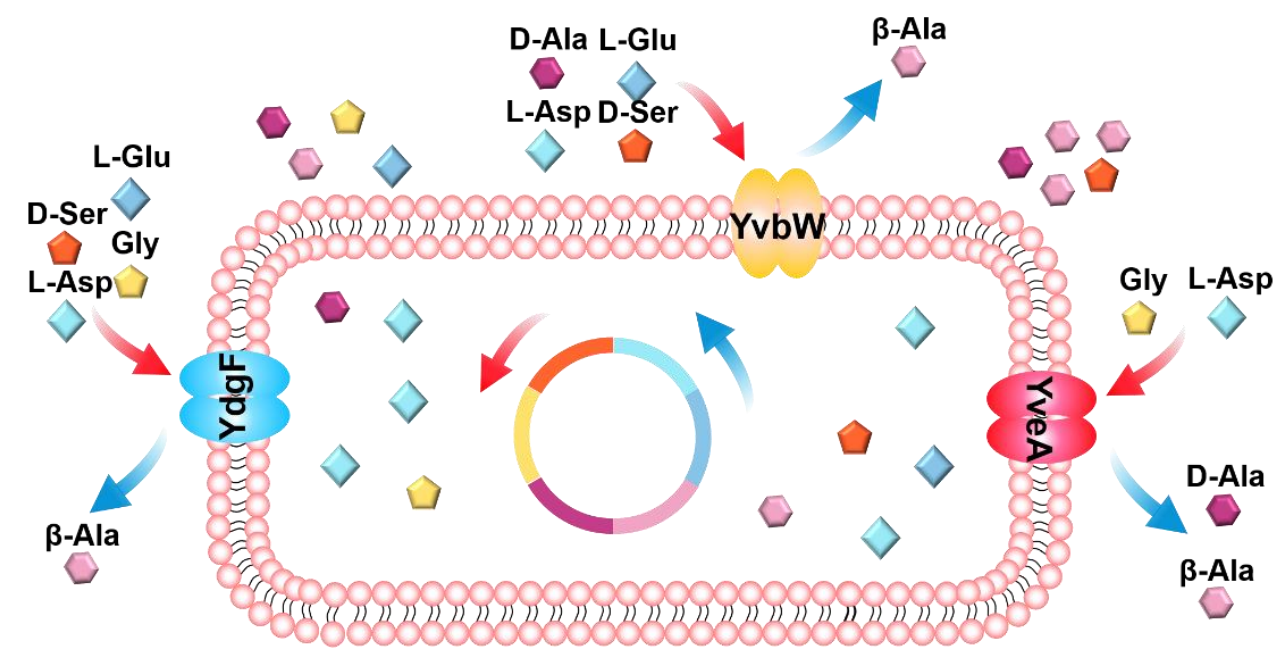

Figure 6. The transport effects of proteins $\mathrm{YdgF}, \mathrm{YvbW}$, and $\mathrm{YveA}$ on amino acids are studied in this paper. Protein $\mathrm{Ydgf}$ can transport L-Asp, D-Ser, Gly, and L-Glu into cells; Protein YvbW can transport D-Ala, L-Glu, L-Asp, and D-Ser into cells; YveA has a specific effect on the cells' absorption of L-Asp and Gly, and these three proteins have the ability to transport $\beta$-Ala out of cells. An amino acid has more than one transporter, which means the other proteins can keep the cells absorbing or excreting amino acids to ensure its survival when the one transport protein is absent. However, transport proteins have certain characteristics, which means the types of amino acids absorbed or excreted by each protein are different, and the ranking of priorities is also different.

We can conclude that the proteins encoded by these three genes constitute amino acid transporters and the final results are not entirely consistent with the prediction. In addition, the permeases can transport more than one type of amino acid. The three proteins have a particular absorption effect on L-aspartic. The protein YdgF has a more pronounced ability of L-Asp absorption after being overexpressed in the cell. Yvea protein has an efflux effect on $\beta$-Ala, and the absence of the yve $A$ gene can enhance $\beta$ - Ala absorption. Protein YdgF can absorb D-Ser, L-Glu, and Gly, and it may have an efflux effect on D-Ala; Yvbw protein can absorb D-Ser and D-Ala; Yvea protein can absorb D-Ser and L-Glu, and it may have an efflux effect on Gly and D-Ala. The growth defects caused by the removal of these three genes from the chromosome lead to reduced uptake ability of free amino acids by the single knockout strains, indicating that these three proteins have a specific effect on the uptake of amino acids in the strain. However, different transport proteins produce different effects in alleviating the growth defect. In strains where the $\mathrm{YdgF}$ gene has been knocked out, the overexpressed protein $\mathrm{YdgF}$ will alleviate the growth defect in later stages of growth, while the complementary expression of YveA alleviates growth defect in the early stages. The specific growth rate was always higher than that of strain BlpHY, while the complementary expression of protein $\mathrm{YvbW}$ and strain growth returned to normal. The reason may be the different uptake mechanisms of L-Asp of the three proteins. In addition, after knocking out the single gene, the bacteria can still grow slowly, which indicates that apart from these three proteins, there are other unreported L-Asp transport mechanisms on the cell membrane of B. licheniformis, and L-Asp is absorbed for cell growth.

B. licheniformis has significant advantages in biological production and is a very suitable object for whole-cell catalysis research. At present, there is little research on licheniformis as a whole-cell catalyst. As an efficient production method, whole-cell catalysis is essentially catalyzed by enzymes in cells [40]. It is a biocatalytic process that falls between fermentation and extracted enzyme catalysis. Compared with free enzymes, whole-cell catalysis has many advantages; for instance, the cell has a complete multi-enzyme system that can realize enzyme cascade reaction. The reaction solution after cell removal is simple in composition and is easy to purify and examine. Moreover, the cell membrane functions as a barrier, which propones the contact between substrate and enzyme. However, there are still many problems in whole-cell catalysis, such as the permeability of cell membrane 
to substrates or enzymes, the accumulation of by-products and degradation caused by byproducts, the uncertainties in the catalytic reaction process, etc., which hinder its further adoption in the industry. Transforming the ability of cell membrane to transport amino acids, improving the efficiency of whole-cell catalysts, and using genetic engineering to screen and transform various cell catalysts will be the most effective way to resolve the issues [41-45]. In this study, the function of transporters was studied through whole-cell catalysis. The cells that changed the expression of the transporters were collected, and the whole-cell catalyst with changed amino acid transport capacity was obtained, which can be used as a catalyst in generating other products in the future. This paper also puts forward some ideas on obtaining the whole-cell catalyst with a modified cell membrane for amino acid production and provides insights into how B. licheniformis is used as a wholecell catalyst.

\section{Materials and Methods}

4.1. Bacterial Strains, Plasmids, and Growth Conditions

The bacterial strains and plasmids used in this study are listed in Table 1, and the primers used are listed in Table2. The B. licheniformis CICIM B1391 was used as a cloning host. Cells were grown at $37{ }^{\circ} \mathrm{C}$ in lysogeny broth medium $(10 \mathrm{~g} / \mathrm{L}$ tryptone, $5 \mathrm{~g} / \mathrm{L}$ yeast extract, $10 \mathrm{~g} / \mathrm{L} \mathrm{NaCl}, 15 \mathrm{~g} / \mathrm{L}$ agar when it is solid medium), enrichment medium (FP321 (yeast peptone) $20 \mathrm{~g} / \mathrm{L}, \mathrm{FM} 408$ (yeast extract) $10 \mathrm{~g} / \mathrm{L},\left(\mathrm{NH}_{4}\right)_{2} \mathrm{HPO}_{4} 75 \mathrm{mmol} / \mathrm{L}$, $\mathrm{K}_{2} \mathrm{HPO}_{4} \bullet 3 \mathrm{H}_{2} \mathrm{O} 40 \mathrm{mmol} / \mathrm{L}, \mathrm{KH}_{2} \mathrm{PO}_{4} 10 \mathrm{mmol} / \mathrm{L}, \mathrm{CaCl}_{2} 4.5 \mathrm{mmol} / \mathrm{L}, \mathrm{MgSO}_{4} \cdot 7 \mathrm{H}_{2} \mathrm{O} 2 \mathrm{mmol} / \mathrm{L}$ ) [46] or minimal medium $\left(\mathrm{NaCl} 0.643 \mathrm{~g} / \mathrm{L},\left(\mathrm{NH}_{4}\right)_{2} \mathrm{SO}_{4} 0.496 \mathrm{~g} / \mathrm{L}, \mathrm{MgSO}_{4} \cdot 7 \mathrm{H}_{2} \mathrm{O} 0.102 \mathrm{~g} / \mathrm{L}\right.$, $\left.\mathrm{K}_{2} \mathrm{SO}_{4} 0.610 \mathrm{~g} / \mathrm{L}, \mathrm{NaH}_{2} \mathrm{PO}_{4} 2.280 \mathrm{~g} / \mathrm{L}, \mathrm{Na}_{2} \mathrm{HPO}_{4} 4.401 \mathrm{~g} / \mathrm{L}\right)$ with restricted carbon and nitrogen sources. When required, ampicillin $(100 \mu \mathrm{g} / \mathrm{mL})$, kanamycin $(30 \mu \mathrm{g} / \mathrm{mL})$, tetracycline $(20 \mu \mathrm{g} / \mathrm{mL})$ were added. When needed, L-Asp at a final concentration of $2 \mathrm{~g} / \mathrm{L}$ was added to the minimal medium for growth tests.

Table 2. Oligonucleotides used in this study

\begin{tabular}{ll}
\hline Primers & Sequence \\
\hline$y v b W-\mathrm{F}$ & CGGGGTACCCCGATGGAGAAAGACATGCAGAAGCTCG \\
yveA-F & CGGGGTACCCCGTTGTCAAATCAGGGCAATTTCAAAA \\
yveA-R & GCGTCGACGTCTTTAAACGGTTTCTTCTTTTTTCTCA \\
$y d g F-\mathrm{F}$ & CGGGGTACCCCGGTGACAGAAGATGTAACTGACAACG \\
$y d g F-\mathrm{R}$ & GGAAGATCTTCCCTACACTTGCTGTGACTTAGGTTT \\
Kan-M-F & GAGCTGTTTGAATATGCAGGCAAATGGCGTAATATTCGTG \\
Kan-M-R & TTCTACGATAAGGGCACAAATCGCATCGTGGAACGTTT \\
$y d g F L-X h o I-F$ & CCCAAGCTTGGGTCATCATCCGCTTGCCGT \\
$y d g F R-H i n d I I I-R$ & CCGCTCGAGCCTCGGGCCTCCCGTTTTT \\
FFRT-KpnI-Kan-F & CGGGGTACCCCGGAAGTTCCTATTCCGAAGTTCCTATTCTCT \\
& AGAAAGTATAGGAACTTCGGC \\
FFRT-SalI-Kan-R & GCGTCGACGTCTTGGCCATAGCGGCCGCGGAAGTTCCTATA \\
& CTTTCTAGAGAATAGGAACTTCGGAATAGGAACTTCCAC \\
& GCGTCGACGTCTTGGCCATAGCGGCCGCGAAACCTAAGTCA \\
& CAGCAAGTG \\
\hline
\end{tabular}




\begin{tabular}{|c|c|}
\hline$y d g F-S a l I-F$ & CGGGGTACCCCGCAGTTACATCTTCTGTCAC \\
\hline$y d g F-\mathrm{L}-\mathrm{F}$ & GCCAGCCGACGTATTCACAAGAACA \\
\hline$y d g F-\mathrm{L}-\mathrm{R}$ & TTTTGTTCAGCTTTCGTTCCTCCTA \\
\hline$y v b W L-X h o I-F$ & CCGCTCGAGCGGAGCATAATCCCTCCCGAACCGATGC \\
\hline yvbWR-SalI-R & GCGTCGACGTCTTCCCTTGTATTTTCCAATGGGAAAGG \\
\hline \multirow{2}{*}{ WFRT-NheI-Kan-F } & CTAGCTAGCTAGATCGAAGTTCCTATTCCGAAGTTCCTATTC \\
\hline & TCTAGAAAGTATAGGAACTTCGGC \\
\hline \multirow{2}{*}{ WFRT-EcoRI-Kan-R } & CCGGAATTCCGGATCGAAGTTCCTATACTTTCTAGAGAATA \\
\hline & GGAACTTCGGAATAGGAACTTCCAC \\
\hline$y v b W-N h e I-R$ & CTAGCTAGCTAGCGTCCGCTTCTTAAAAAAAGGCTTG \\
\hline$y v b W-E c o R I-F$ & CCGGAATTCCGGCTCCATCTATGTTCACTTCCTCTAG \\
\hline$y v b W-\mathrm{L}-\mathrm{F}$ & ACATTGCCGGACGGCTTAAAATACTGGCGGAGTTC \\
\hline$y v b W-\mathrm{L}-\mathrm{R}$ & CGGTTCACACTCTATCATCGTTAAAATATTTTGTAAAGT \\
\hline yveAL-XhoI-F & CCGCTCGAGCGGATTGAATGCCGGTGTACCGCTTGTT \\
\hline yveAR-PstI-R & TGCACTGCAGTGCACTTGGAACGGGATGCTTCCCAAACA \\
\hline \multirow{2}{*}{ AFRT-KpnI-Kan-F } & CGGGGTACCCCGATCGAAGTTCCTATTCCGAAGTTCCTATTC \\
\hline & TCTAGAAAGTATAGGAACTTCGGC \\
\hline \multirow{2}{*}{ AFRT-SalI-Kan-R } & GCGTCGACGTCTTATCGAAGTTCCTATACTTTCTAGAGAATA \\
\hline & GGAACTTCGGAATAGGAACTTCC \\
\hline yveA-KpnI-R & CGGGGTACCCCGGACAAATCACTTCCTCCTTTTTAAT \\
\hline yveA-SalI-F & GCGTCGACGTCTTTAAATAAGAATCCCCCGCGTATGGA \\
\hline yveA-L-F & CCGGAATTTTATCATATGTGCATCGAAGCATTCAG \\
\hline yveA-L-R & ACCTTGATACTAATGATGTGTCCTTCACACAATAA \\
\hline
\end{tabular}

The shuttle plasmid pHY300-PLK was used as the vector to construct the recombinant plasmid. The $y d g F, y v b W$, and $y v e A$ genes on the genome of B. licheniformis CICIM B1391 were amplified through PCR using the Phanta enzyme (Vazyme Biotech Co., Ltd. $2 \times$ Phanta Master Mix). Primers produced in this study are listed in Table 2. The PCR system $(50 \mu \mathrm{L})$ contained $25 \mu \mathrm{L}$ of Taq, $22 \mu \mathrm{L}$ of redistilled water, $1 \mu \mathrm{L}$ of upstream primer, $1 \mu \mathrm{L}$ of downstream primer, and $1 \mu \mathrm{L}$ of genomic DNA extracted from $B$. licheniformis CICIM B1391. The plasmids used and constructed in this study are listed in Table 1. E.coli JM109 was used for plasmid preparation by selecting transformants on Luria-Bertani (LB) agar plates supplemented with ampicillin $(100 \mu \mathrm{g} / \mathrm{mL})$. The plasmids were extracted and transformed into a competent cell of $B$. licheniformis with an electric shock at a voltage of about $2000 \mathrm{~V}$. The transformants were cultured in a recovery medium ( $\mathrm{LB}+0.5 \mathrm{M}$ sorbitol $+0.38 \mathrm{M}$ mannitol $)$ at $37{ }^{\circ} \mathrm{C}$ for $3 \mathrm{~h}$ and selected with tetracycline $(20 \mu \mathrm{g} / \mathrm{mL})$ resistance plate [47]. This study used three promoters, i.e., mannitol inducible promoter PmtlA, constitutive promoter Pshuttle09, and Pshuttle09 with xylose inducible site Pshuttle09-XBS, which can mediate protein overexpression in B. licheniformis [38, 39]. 
In this study, FLP/FRT recombination system is used to knock out related genes. The constructed knockout plasmids pNZTT-FFKF, pNZTT-WFKF, and pNZTT-AFKF were transferred into B. licheniformis to obtain strains BlpNZTT-FFKF, BlpNZTT-WFKF, and BlpNZTT-AFKF. The strain was activated at a temperature of $30{ }^{\circ} \mathrm{C}$ and a centrifugation speed of $200 \mathrm{rpm}$. $300 \mu \mathrm{L}$ of the sample was transferred to $15 \mathrm{ml} \mathrm{LB}$ of broth, which was cultured for one generation (14 20 h/generation) at $42{ }^{\circ} \mathrm{C}$ and a centrifugation speed of $250 \mathrm{rpm}$. The bacterial solution was streaked with kanamycin, cultured at $37{ }^{\circ} \mathrm{C}$ until the single colony grows, and one more generation was inoculated before each time of plate streaking. If there is no single colony, it should be reactivated. Then it has to be verified whether the LB plate with kanamycin can obtain the strain without the target gene. When the PCR products of left, right, and double exchanges on the genome display clear bands and correct sizes on nucleic acid electrophoresis, the single colony may be the strain where the target gene has been knocked out. Then the single colony is streaked and amplified on the LB plate containing kanamycin, with colonies not growing on the LB plate containing tetracycline verified one by one. The genome of the strain was extracted, amplified, and sequenced with the upstream and downstream primers of the knockout gene to confirm whether the target gene had been removed. If the nucleic acid electrophoresis of the three PCR and the DNA sequencing results were correct, the double exchange strains BldF, BldW, BldA were obtained. If the double exchange strains are not obtained, strains BlpNZTT-FFKF, BlpNZTT-WFKF, and BlpNZTT-AFKF should be reactivated $[48,49]$.

\subsection{Method of Cell Density Determination}

In this study, the OD value of culture at $600 \mathrm{~nm}$ was used to express the cell concentration. Shake up the bacterial solution and dilute it to a certain concentration. Measure its OD value at $600 \mathrm{~nm}$ with an ultraviolet spectrophotometer and use a blank medium with the same dilution ratio as the control. Subtract the absorption value of the control and multiply it by the dilution ratio to obtain the OD600 [46].

\subsection{Method of Whole-cell Catalyst}

The strain was activated by streaking on the corresponding antibiotic-resistant plate and was cultured for 20 hours. A single colony was selected and inoculated into an LB medium for 16 hours. The activated bacterial solution was inoculated into an enrichment medium and cultured until OD600 was about 20. The bacterial solution was poured into a $50 \mathrm{ml}$ centrifuge tube, washed twice with minimal medium cooled with ice in advance, and then suspended in the minimal medium of the same volume. If the cells have antibiotic resistance, certain antibiotics can be added to prevent bacterial infection. The cell solution was pre-cultured at a centrifugation speed of $120 \mathrm{rpm}$ and a temperature of $37{ }^{\circ} \mathrm{C}$ for $30 \mathrm{~min}$, before the addition of the amino acid solution of a certain final concentration. The orifice of the centrifuge tube was then sealed with sealing film and cultured at $120{ }^{\circ} \mathrm{C}$ for 16 hours [40-44].

\subsection{HPLC}

Centrifuge the bacterial solution and take the supernatant. $0.22 \mu \mathrm{M}$ of the membrane was used to filtrate the supernatant, before the filtered liquid was diluted to an amino acid concentration of $1 \mathrm{~g} / \mathrm{L}$. OPA pre-column derivatization method was used to separate different components in the sample by gradient elution. Most amino acids can be detected at the $338 \mathrm{~nm}$ UV wavelength. This study adopts external standards. Prepare a $1 \mathrm{~g} / \mathrm{L}$ amino acid standard solution, and then dilute it to 5 concentrations, measure the retention time to determine the amino acid, and measure the peak area to get the concentration of the amino acid in the solution. 
Supplementary Materials: The following materials are available at www.mdpi.com/xxx/s1, Figure S1: Cell growth in minimal medium with free L-Asp as the only carbon and nitrogen source.

Author Contributions: Conceptualization, Y.L. and G.S.; methodology, H.W.; validation, F.X. and Y.Z.; data curation, H.W.; writing - original draft preparation, H.W.; writing-review and editing, Y.L.

Funding: This work was supported by National Key Research \& Development Program of China (2020YFA0907700, 2018YFA0900300, and 2018YFA0900504), the National Natural Foundation of China (32172174, 31401674), Postgraduate Research \& Practice Innovation Program of Jiangsu Province (SJCX20_0746), the National First-Class Discipline Program of Light Industry Technology and Engineering (LITE2018-22), and the Top-notch Academic Programs Project of Jiangsu Higher Education Institutions.

Conflicts of Interest: The authors declare no conflict of interest.

\section{References}

1. Park, J. H.; Lee, K. H.; Kim, T. Y.; Lee, S. Y., Metabolic engineering of Escherichia coli for the Production of L-valine Based on Transcriptome Analysis and in Silico Gene Knockout Simulation. Proc Natl Acad Sci U S A 2007, 104, (19), 7797-7802.

2. Zakataeva, N. P.; Aleshin, V. V.; Tokmakova, I. L.; Troshin, P. V.; Livshits, V. A., The Novel Transmembrane Escherichia coli Proteins Involved in the Amino Acid Efflux. FEBS Letters 1999, 452, (3), 228-232.

3. Trotschel, C.; Deutenberg, D.; Bathe, B.; Burkovski, A.; Kramer, R., Characterization of Methionine Export in Corynebacterium glutamicum. J Bacteriol 2005, 187, (11), 3786-94.

4. Shimizu, H.; Hirasawa, T., Production of Glutamate and Glutamate-Related Amino Acids: Molecular Mechanism Analysis and Metabolic Engineering. In Amino Acid Biosynthesis Pathways, Regulation and Metabolic Engineering, Wendisch, V. F., Ed. Springer Berlin Heidelberg: Berlin, Heidelberg, 2007; pp 1-38.

5. Radmacher, E.; Stansen, K. C.; Besra, G. S.; Alderwick, L. J.; Maughan, W. N.; Hollweg, G.; Sahm, H.; Wendisch, V. F.; Eggeling, L., Ethambutol, A Cell Wall Inhibitor of Mycobacterium tuberculosis, Elicits L-glutamate Efflux of Corynebacterium glutamicum. Microbiology 2005, 151, (5), 1359-1368.

6. Park, S.; Imlay, J. A., High Levels of Intracellular Cysteine Promote Oxidative DNA Damage by Driving the Fenton Reaction. J Bacteriol 2003, 185, (6), 1942-50.

7. Vrljic, M.; Sahm, H.; Eggeling, L., A New Type of Transporter with a New Type of Cellular Function: L-lysine Export from Corynebacterium glutamicum. Mol Microbiol 1996, 22, (5), 815-826.

8. $\quad$ BRÖER, S.; KRÄMER, R., Lysine Excretion by Corynebacterium glutamicum. Eur J Biochem 1991, $202,(1), 137-143$.

9. Liu, Q.; Liang, Y.; Zhang, Y.; Shang, X.; Liu, S.; Wen, J.; Wen, T., YjeH Is a Novel Exporter of L-Methionine and BranchedChain Amino Acids in Escherichia coli. Appl Environ Microbiol 2015, 81, (22), 7753-66.

10. den Hengst, C. D.; Groeneveld, M.; Kuipers, O. P.; Kok, J., Identification and Functional Characterization of the Lactococcus lactis CodY-regulated Branched-chain Amino Acid Permease BcaP (CtrA). J Bacteriol 2006, 188, (9), 3280-9.

11. Belitsky, B. R., Role of Branched-chain Amino Acid Transport in Bacillus subtilis CodY Activity. J Bacteriol 2015, 197, (8), 1330-8.

12. Ihara, K.; Sato, K.; Hori, H.; Makino, Y.; Shigenobu, S.; Ando, T.; Isogai, E.; Yoneyama, H., Expression of the alaE Gene is Positively Regulated by the Global Regulator Lrp in Response to Intracellular Accumulation of L-alanine in Escherichia coli. J Biosci Bioeng 2017, 123, (4), 444-450.

13. Kennerknecht, N.; Sahm, H.; Yen, M. R.; Patek, M.; Saier Jr, M. H., Jr.; Eggeling, L., Export of L-isoleucine from Corynebacterium glutamicum: a Two-gene-encoded Member of a New Translocator Family. J Bacteriol 2002, 184, (14), $3947-56$.

14. Kim, S.; Ihara, K.; Katsube, S.; Hori, H.; Ando, T.; Isogai, E.; Yoneyama, H., Characterization of the L-alanine Exporter AlaE of Escherichia coli and its Potential role in Protecting cells from a Toxic-level Accumulation of L-alanine and its Derivatives.

Microbiologyopen 2015, 4, (4), 632-43. 
15. Kruse, D.; Kramer, R.; Eggeling, L.; Rieping, M.; Pfefferle, W.; Tchieu, J. H.; Chung, Y. J.; Jr Saier, M. H.; Burkovski, A., Influence of Threonine Exporters on Threonine Production in Escherichia coli. Appl Microbiol Biotechnol 2002, 59, (2-3), 205-10.

16. Park, J. H.; Oh, J. E.; Lee, K. H.; Kim, J. Y.; Lee, S. Y., Rational Design of Escherichia coli for L-isoleucine Production. ACS Synth Biol 2012, 1, (11), 532-40.

17. Daßler, T.; Maier, T.; Winterhalter, C.; Böck, A., Identification of a Major Facilitator Protein from Escherichia coli Involved in Efflux of Metabolites of the Cysteine Pathway. Mol Microbiol 2000, 36, (5), 1101-1112.

18. Bellmann, A.; Vrljić, M.; Pátek, M.; Sahm, H.; Krämer, R.; Eggeling, L., Expression Control and Specificity of the Basic Amino Acid Exporter LysE of Corynebacterium glutamicum. Microbiology (Reading, England) 2001, 147, (Pt 7), 1765-1774.

19. Leuchtenberger, W.; Huthmacher, K.; Drauz, K., Biotechnological Production of Amino Acids and Derivatives: Current Status and Prospects. Appl Microbiol Biotechnol 2005, 69, (1), 1-8.

20. Chibata, I.; Tosa, T.; Sato, T., Continuous Production of L-aspartic acid. Appl Biochem Biotechnol 1986, 13, (3), $231-240$.

21. Chibata, I.; Tosa, T.; Sato, T., Immobilized Aspartase-containing Microbial Cells: Preparation and Enzymatic Properties. Appl Microbiol 1974, 27, (5), 878-885.

Song, C. W.; Lee, J.; Ko, Y. S.; Lee, S. Y., Metabolic Engineering of Escherichia coli for the Production of 3-aminopropionic acid. Metab Eng 2015, 30, 121-129.

23. Feng, Z.; Zhang, J.; Chen, G.; Ge, Y.; Zhang, X.; Zhu, H., Extracellular Expression of L-Aspartate- $\alpha$-Decarboxylase from Bacillus tequilensis and Its Application in the Biosynthesis of $\beta$-Alanine. Appl Biochem Biotechnol 2019, 189, (1), $273-283$.

24. Phengnuam, T.; Suntornsuk, W., Detoxification and Anti-nutrients Reduction of Jatropha Curcas Seed Cake by Bacillus fermentation. J Biosci Bioeng 2013, 115, (2), 168-72.

25. Voigt, B.; Schroeter, R.; Schweder, T.; Jurgen, B.; Albrecht, D.; van Dijl, J. M.; Maurer, K. H.; Hecker, M., A Proteomic View of Cell Physiology of the Industrial Workhorse Bacillus licheniformis. J Biotechnol 2014, 191, 139-49.

26. Shi, J.; Zhan, Y.; Zhou, M.; He, M.; Wang, Q.; Li, X.; Wen, Z.; Chen, S., High-level Production of Short Branched-chain Fatty Acids from Waste Materials by Genetically Modified Bacillus licheniformis. Bioresour Technol 2019, 271, 325-331.

27. Zhu, C.; Xiao, F.; Qiu, Y.; Wang, Q.; He, Z.; Chen, S., Lichenysin Production is Improved in codY Null Bacillus licheniformis by Addition of Precursor Amino Acids. Appl Microbiol Biotechnol 2017, 101, (16), 6375-6383.

28. Zhu, J.; Cai, D.; Xu, H.; Liu, Z.; Zhang, B.; Wu, F.; Li, J.; Chen, S., Enhancement of Precursor Amino Acid Supplies for Improving Bacitracin Production by Activation of Branched Chain Amino Acid Transporter BrnQ and Deletion of its Regulator Gene lrp in Bacillus licheniformis. Synth Syst Biotechnol 2018, 3, (4), 236-243.

29. Liu, E.; Zheng, H.; Hao, P.; Konno, T.; Kume, H.; Ye, 1.; Oda, M.; Suzuki, K.; Ji, Z.-S., Acquisition of Amino Acids by Lactobacillus delbrueckii subsp. bulgaricus 2038 when Grown in the Presence of Casein. Int Dairy J 2014, 35, (2), 145-152.

30. Kikukawa, T.; Miyauchi, S.; Araiso, T.; Kamo, N.; Nara, T., Anti-parallel Membrane Topology of Two Components of EbrAB, a Multidrug Transporter. Biochem Biophys Res Commun 2007, 358, (4), 1071-5.

31. Duran, A. M.; Meiler, J., Inverted Topologies in Membrane Proteins: a Mini-review. Comput Struct Biotechnol J 2013, 8, e201308004.

32. Liu, E.; Zheng, H.; Shi, T.; Ye, L.; Konno, T.; Oda, M.; Shen, H.; Ji, Z.-S., Relationship Between Lactobacillus bulgaricus and Streptococcus thermophilus under Whey Conditions: Focus on Amino Acid Formation. Int Dairy J 2016, 56, 141-150.

33. Daley Daniel, O.; Rapp, M.; Granseth, E.; Melén, K.; Drew, D.; von Heijne, G., Global Topology Analysis of the Escherichia coli Inner Membrane Proteome. Science 2005, 308, (5726), 1321-1323.

34. Rollins, S. M., Induced Transcriptional Expression of Bacillus subtilis Amino Acid Permease yvbW in Response to Leucine Limitation. Advances in Microbiology 2014, 04, (08), 484-492.

35. Cai, D.; Zhu, J.; Li, Y.; Li, L.; Zhang, M.; Wang, Z.; Yang, H.; Li, J.; Yang, Z.; Chen, S., Systematic Engineering of Branch chain Amino Aacid Supply Modules for the Enhanced Production of Bacitracin from Bacillus licheniformis. Metab Eng Commun 2020, 11, e00136. 
36. Lorca, G.; Winnen, B.; Saier, M. H., Jr., Identification of the L-aspartate Transporter in Bacillus subtilis. J Bacteriol 2003, 185, (10), 3218-22.

37. Saier, J., Milton H., Families of Transmembrane Transporters Selective for Amino Acids and Their Derivatives. Microbiology 2000, 146, (8), 1775-1795.

38. Xiao, F.; Li, Y.; Zhang, Y.; Wang, H.; Zhang, L.; Ding, Z.; Gu, Z.; Xu, S.; Shi, G., Construction of a Novel Sugar Alcoholinducible Expression System in Bacillus licheniformis. Appl Microbiol Biotechnol 2020, 104, (12), 5409-5425.

39. Driessen, A.; Yang, M.; Zhang, W.; Ji, S.; Cao, P.; Chen, Y.; Zhao, X., Generation of an Artificial Double Promoter for Protein Expression in Bacillus subtilis through a Promoter Trap System. PLoS ONE 2013, 8, (2), e56321.

40. Hori, H.; Yoneyama, H.; Tobe, R.; Ando, T.; Isogai, E.; Katsumata, R., Inducible L-alanine Exporter Encoded by the Novel Gene ygaW (alaE) in Escherichia coli. Appl Environ Microbiol 2011, 77, (12), 4027-34.

41. Gupta, R.; Noronha, S. B., Utilization of Bacillus subtilis Cells Displaying a Glucose-tolerant beta-glucosidase for Whole-cell Biocatalysis. Enzyme Microb Technol 2020, 132, 109444.

42. Pinto, A.; Contente, M. L.; Tamborini, L., Advances on Whole-cell Biocatalysis in Flow. Curr Opin Green Sustain Chem 2020, $25,100343$.

43. Talukder, M. M. R.; Min, P. S.; Jae, C. W., Integration of Cell Permeabilization and Medium Engineering for Enhanced Enantioselective Synthesis of Ethyl-S-3-hydroxy-3-phenylpropanoate (S-EHPP). Biochem. Eng. J 2019, 148, $24-28$.

44. Wachtmeister, J.; Rother, D., Recent Advances in Whole Cell Biocatalysis Techniques Bridging from Investigative to Industrial Scale. Curr Opin Biotechnol 2016, 42, 169-177.

45. Sun, Y.; Hu, X.; Guo, D.; Shi, C.; Zhang, C.; Peng, X.; Yang, H.; Xia, X., Disinfectant Resistance Profiles and Biofilm Formation Capacity of Escherichia coli Isolated from Retail Chicken. Microb Drug Resist 2019, 25, (5), 703-711.

46. Li, Y.; Liu, X.; Zhang, L.; Ding, Z.; Xu, S.; Gu, Z.; Shi, G., Transcriptional Changes in the Xylose Operon in Bacillus licheniformis and Their Use in Fermentation Optimization. Int J Mol Sci 2019, 20, (18).

47. Xiao, F.; Li, Y.; Zhang, Y.; Wang, H.; Zhang, L.; Ding, Z.; Gu, Z.; Xu, S.; Shi, G., A new CcpA Binding Site Plays a Bidirectional Role in Carbon Catabolism in Bacillus licheniformis. iScience 2021, 24, (5), 102400.

48. Tan, X.; Liang, F.; Cai, K.; Lu, X., Application of the FLP/FRT Recombination System in Cyanobacteria for Construction of Markerless Mutants. Appl Microbiol Biotechnol 2013, 97, (14), 6373-6382.

49. Sanchez-Martinez, C.; Perez-Martin, J., Site-specific Targeting of Exogenous DNA into the Genome of Candida Albicans Using the FLP Recombinase. Mol Genet Genomics 2002, 268, (3), 418-24. 